\title{
GERMINATION RATE AND LONGEVITY OF SEEDS OF ALDROVANDA VESICULOSA AND UTRICULARIA VULGARIS
}

LUBOMÍR ADAMEC • Institute of Botany of the Czech Academy of Sciences • Dukelská 135 • CZ-379

82 Třebon̆ $•$ Czech Republic •lubomir.adamec@ibot.cas.cz

Keywords: Aquatic carnivorous plants, field bag experiment, seed germination, life-span, seed bank.

\section{Introduction}

The ecological group of aquatic carnivorous plants includes monotypic Aldrovanda vesiculosa L. (Droseraceae) and around 60 species of Utricularia L. (Lentibulariaceae). Although the majority of aquatic carnivorous species are perennials and propagate mainly vegetatively by branching, shoot fragmentation and turions, the majority of them also set seeds (Taylor 1989; Cross 2012; Cross et al. 2016, 2018). While these modes of vegetative propagation in temperate species ensure the production of high plant biomass at sites during each season and turions also serve population overwintering (Adamec 1999a, 2011), functional seeds form a viable seed bank as a safety measure to overcome crucial habitat disturbances (mainly drought) leading to biomass extinction and are usually spread by water birds to colonize new potential distant sites (Santamaria 2002; Cross 2012; Cross et al. 2016, 2018).

Temperate native European and introduced North American populations of Aldrovanda vesiculosa flower relatively commonly under optimum habitat conditions (Front Cover) but their seed set is rare and limited (Adamec \& Tichý 1997; Adamec 1999b; Cross 2012; Cross et al. 2015, 2016). Aldrovanda produces ovoid, rigid seeds 1.2-1.5 mm long with highly developed honeycomb-like exotesta and it is assumed that they are spread via water birds (Cross 2012; Cross et al. 2016, 2018). Older fragmentary pieces of knowledge on Aldrovanda's seed set and germination features (see Cross 2012 and the references therein) have recently been complemented by Cross et al. (2016). For freshly collected seeds from SW Australia, the optimum temperature for germination was $25^{\circ} \mathrm{C}$ in light, while no germination was observed in darkness. Germination was also the best with ethylene and after 8 weeks of cold stratification $\left(5^{\circ} \mathrm{C}\right)$ interrupted by an 8 -week warm period at $25^{\circ} \mathrm{C}$; control seeds were kept at $5^{\circ} \mathrm{C}$ in darkness. To estimate seed longevity, when fresh seeds in bags were buried in sediment $1 \mathrm{~cm}$ deep at a natural site for 6 months, only $20 \%$ of the seeds survived and after burial for 1 year, all seeds died. Thus, this result can be interpreted as rather limited seed longevity under natural conditions of bottom sediment which would prevent the existence of a seed bank. On the other hand, at a natural Hungarian site, population recruitment after a several-year break and lake drying out occurred (Adamec, unpubl. data), which confirms a functioning of seed bank for several (ca. 10) years. Moreover, seeds stored in a dry state reduced partly their germination rate after 1 month, but completely after 1 year. Similarly, freezing fresh seeds to $-18^{\circ} \mathrm{C}$ for only $24 \mathrm{~h}$ reduced the germination rate by $10-45 \%$, while freezing for 3 months completely inhibited germination (Cross et al. 2016). Physiological dormancy is stated for Aldrovanda seeds (Cross et al. 2018).

European populations of Utricularia vulgaris flower and set seeds prolifically (Taylor 1989). The seeds usually ripen in capsules above the surface but fall soon to water and sink to the bottom. The seeds ca. $0.6 \mathrm{~mm}$ large have a morpho-physiological dormancy (Holzbauerová 2015; Cross et al. 2018). Similar to Aldrovanda, U. vulgaris seeds germinate better at a higher temperature of $25^{\circ} \mathrm{C}$ and in light and break their dormancy after weeks of cold stratification, with ethylene, or 
after a frost treatment (Holzbauerová 2015). Unlike Aldrovanda, seeds stored both under water or in dry state for 1-2 years germinated equally well. In U. vulgaris, a persistent seed bank exists. Gálová \& Hájková (2014) found native seedlings of this species at a former fishpond site in $\mathrm{S}$ Moravia, Czech Republic, where the species was considered extinct for ca. 23 years. From organic bottom sediments dated between 70-100 years old, released U. vulgaris seeds germinated in light as soon as 6 days. Pieces of evidence thus indicate that the longevity of the Aldrovanda seed bank is very variable and much shorter than that of $U$. vulgaris. The aim of this study is to compare the survival and germination rate of Aldrovanda and $U$. vulgaris seeds exposed in nylon bags on top of a bottom sediment or slightly buried in it in a sand-pit pool in the Czech Republic for 11 months (cf. Cross et al. 2016).

\section{Methods}

The experiment was conducted in a ca. $250 \mathrm{~m}^{2}$ shallow sand-pit pool within the complex of excavated sand-pit Cep I near Suchdol nad Lužnicí in S Bohemia, Czech Republic (4855'08.5"N, $14^{\circ} 53^{\prime} 3.1$ "E, $450 \mathrm{~m}$ a.s.1., see Fig. 1). The pool is about 15 years old, about 50-60 cm deep and the bottom sediment around 5-10 cm deep consists of fine clayish acidic sand mixed with organic substrate from decomposed plant litter. The pool is supplied with rainwater coming from a near terrace and its quite transparent water is extremely soft (electrical conductivity between $22-187 \mu \mathrm{S} \mathrm{cm}^{-1}$,

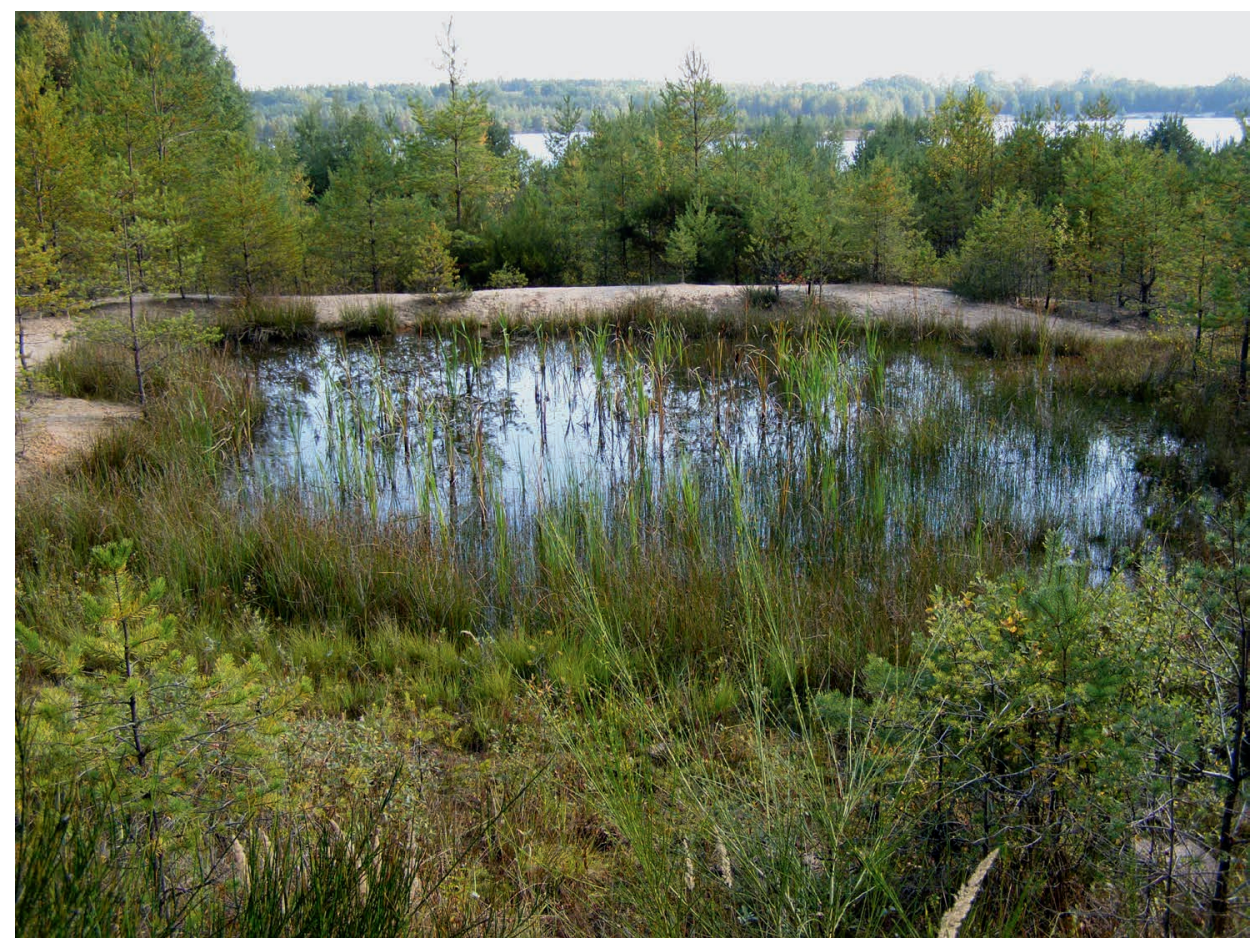

Figure 1: Shallow pool in a sand-pit Cep I near Suchdol nad Lužnicí in S Bohemia, Czech Republic, is inhabited by introduced Aldrovanda vesiculosa and Utricularia bremii. The seed exposure experiment was conducted near the left shore. 
usually only 30-50 $\mu \mathrm{S} \mathrm{cm}^{-1}$ ), slightly humic (dystrophic) and oligotrophic; pH ca. 6-7 (for details, see Adamec 2009; Cross et al. 2016). Native plant dominants in the pool were Eleocharis palustris, E. acicularis, Potamogeton natans, Juncus bulbosus, and J. effusus. Introduced dominants were Utricularia bremii, Luronium natans, and Potamogeton alpinus (Adamec \& Kučerová 2013). Since 2009, also Hungarian red plants of Aldrovanda have been growing in the pool. In 2013 and 2014, its population contained at least 5000 plants and in both summer seasons each, at least 1000 plants flowered here and hundreds of ripe capsules were collected (Cross et al. 2016). In the 2015 season, its population was drastically decimated by the unknown (perhaps fungal) 'Aldrovanda disease' (see Adamec 2007) and only dozens of plants have survived up to now.

Ripe seeds of Aldrovanda were collected from this pool in summer 2014 and the clean seeds were stored in humic water in a refrigerator for about one year before the experiment. Ripe seeds of $U$. vulgaris were freshly collected from an outdoor culture in the Institute of Botany at Tr̆ebon̆ in summer 2015 and stored in dry state in a refrigerator. Twenty Aldrovanda seeds were checked for mechanical stiffness and 40 U. vulgaris seeds were put into each of 10 fine nylon bags of $3.5 \times 3.5$ $\mathrm{cm}$ (mesh size $150 \mu \mathrm{m}$ ) and the tagged bags with seeds were closed with a flame. Five bags with the seeds were connected with each other using a nylon line to form a star (Fig. 2). On 1 Sep. 2015, five of the bags were placed on top soil in the pool ca. $40 \mathrm{~cm}$ deep near the shore, while the other five were buried $1-2 \mathrm{~cm}$ in the soft sediment about $25 \mathrm{~cm}$ nearby. Both sets of bags were fixed by a wooden stick. The seeds in the bags were exposed in the pool over winter for 11 months until 30 Jul. 2016. To estimate oxidation-reduction conditions in the exact place of seed exposure of both

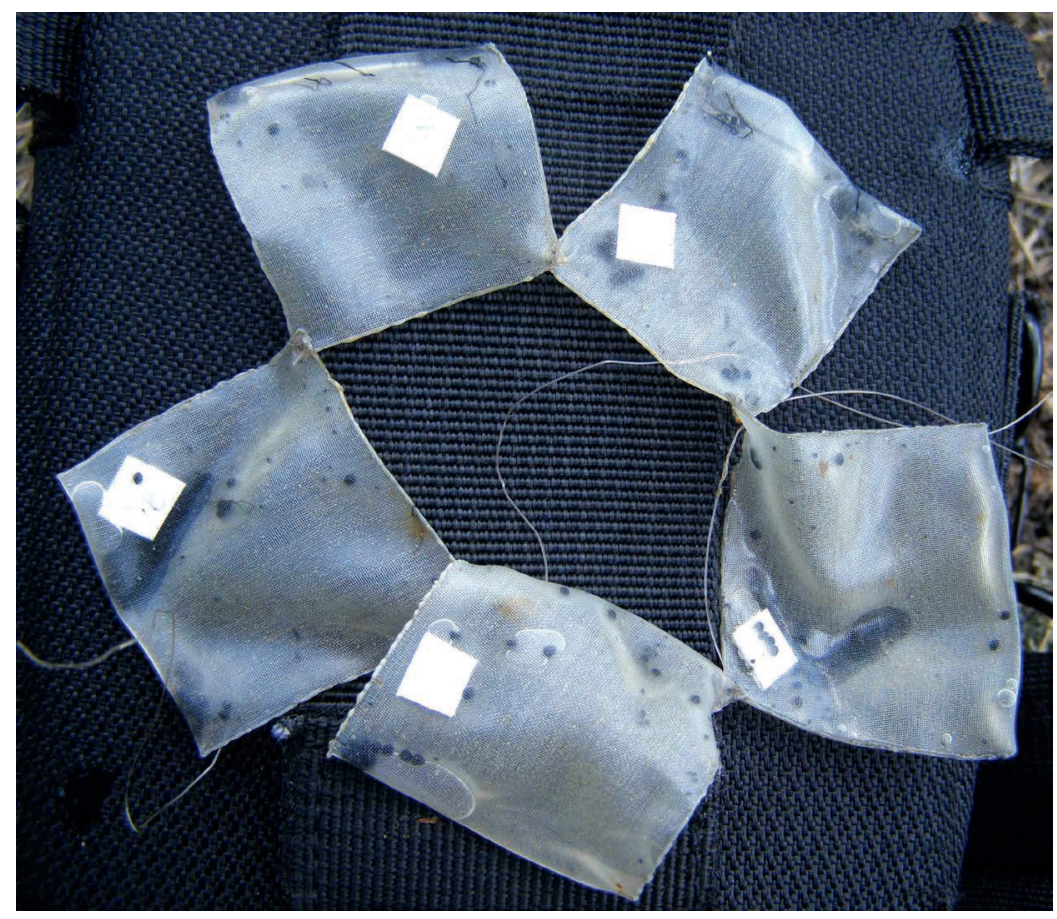

Figure 2: Fine nylon bags with Aldrovanda and U. vulgaris seeds after they were taken out of the shallow sediment after the 11-month exposure. 
variants, the electrical redox potential was measured on the top soil and 1-2 cm deep in the sediment near the exposed bags on $9 \mathrm{Jul}$. 2016. Platinum and $\mathrm{Ag} / \mathrm{AgCl}$ reference electrode and a portable digital $\mathrm{mV}$ meter were used for the measurements. Ten parallel redox potential measurements were conducted for each variant and the potential of the reference electrode $(218 \mathrm{mV})$ was subtracted from the measured value.

On 30 July 2016, the seed exposure was terminated, the bags were washed by tap water, and the seeds taken out from the bags. Within each bag, just germinating and non-germinating seeds were counted; the remaining seeds were considered damaged as no intact seed could escape from the bags. The remaining clean seeds from each bag were put in a small translucent plastic box in $20 \mathrm{ml}$ of filtered humic water to germinate. All 10 plastic boxes were put into a 3.5-1 miniaquarium filled with tap water which floated in an outdoor $2 \mathrm{~m}^{2}$ plastic container. The seeds in humic water were thus naturally lit and exposed near the water surface at temperatures similar to those in natural habitats. The boxes with the seeds were alternatively exposed outdoors or at ca. $3.5^{\circ} \mathrm{C}$ in darkness in a refrigerator to break seed dormancy (sensu Holzbauerová 2015; Cross et al. 2016). After 4 days of outdoor exposure, they were put into a refrigerator on 3 Aug. 2016 for 3 days until 6 Aug. 2016. Then, after 6 days of outdoor exposure on 12 Aug. 2016, they were put into a refrigerator for 10 days until 22 Aug. 2016. After 9 days outdoors, they were put into a refrigerator on 31 Aug. 2016 for 3 days. On 3 Sep. 2016, they were exposed outdoors for 11 days until 14 Sep. 2016. After 5 days in a refrigerator, on 19 Sep. 2016, they were exposed outdoors for 29 days until 18 Oct. 2016. The remaining seeds then overwintered in a refrigerator for 9 months until 24 Jul. 2017. After another 13-day outdoor exposure, the boxes were put in a refrigerator on 6 Aug. 2017 for 8 days until 14 Aug. 2017. They were then exposed outdoors until 4 Sep. 2017 for 21 days and then put into a refrigerator until 14 Sep. 2017 for 10 days. They were then exposed outdoors until 2 Oct. 2017 for 18 days. At the end of each outdoor exposure, germination of seeds was scored and germinated seeds were removed from the boxes. The cumulative germination rate within each box (bag) is expressed in $\%$ of the original seed count. Means \pm 1 SE intervals are shown for 5 bags within each variant but the data clearly followed a non-normal distribution.

\section{Results and Discussion}

The redox potential on the top soil was $-209.8 \pm 8.7 \mathrm{mV}$, while that $1-2 \mathrm{~cm}$ deep in the bottom was $-376.4 \pm 6.6 \mathrm{mV}$, indicating an anoxic zone in the sediment. Between $3-7 \%$ of seeds were damaged and their testa was ruptured at the conclusion of 11 months of storage in sediment or top soil (Table 1). The difference between both treatments is not marked. The first seeds started rarely germinating only after two short cold/warm stratification treatments. However, the germination was markedly stimulated after the next 11-month cold stratification in a refrigerator as a result of which about $19 \%$ of the seeds germinated in light outdoors (Fig. 3). A further germination was very low. Unlike these results, fresh Aldrovanda seeds did not survive a one-year period of shallow burial in a bottom sediment at an Australian site (Cross et al. 2016).

Only $3-5 \%$ of $U$. vulgaris seeds were damaged after the field exposure in both variants (Table 1). Generally, the germination pattern was very similar to that in Aldrovanda. First U. vulgaris seeds germinated as early as at the end of the field exposure in the bags in the top soil variant. Germination was very low even after two short cold/warm stratification treatments. Seed dormancy was markedly broken after the next 11-month cold stratification and about 37\% seeds germinated in light outdoors afterwards (Fig. 3). Only the next $2-3 \%$ of the seeds germinated by the end of the summer season. 
Table 1. Results of the cumulative germination rate of Aldrovanda vesiculosa (AV) and Utricularia vulgaris (UV) seeds during the 2016 and 2017 seasons. On 1 Sep. 2015, five parallel nylon bags each with 20 seeds of $A$. vesiculosa and 40 seeds of $U$. vulgaris were placed on the top of a loose sediment (variant $\mathrm{T}$ ) and another five bags were buried 1-2 cm deep in the sediment of a shallow sand-pit pool (variant B; see Fig. 1) for 11 months until 30 Jul. 2016. Damaged and germinated seeds were evaluated (in \% of all seeds for each bag, means \pm SE intervals shown, $n=5)$. Seeds of both species were allowed to germinate in natural light in humic water in translucent vials. Light exposure was interrupted by periods of dark cold treatment at $3-4^{\circ} \mathrm{C}$ (see the text).

\begin{tabular}{|c|c|c|c|c|c|c|c|}
\hline \multirow[b]{2}{*}{ Species } & \multicolumn{2}{|c|}{30 Jul. 2016} & $\begin{array}{c}12 \text { Aug. } \\
2016\end{array}$ & $\begin{array}{l}31 \text { Aug. } \\
2016\end{array}$ & $\begin{array}{c}31 \mathrm{Jul} . \\
2017\end{array}$ & $\begin{array}{l}4 \text { Sep. } \\
2017\end{array}$ & $\begin{array}{c}2 \text { Oct. } \\
2017\end{array}$ \\
\hline & Damage & & & ulative ger & ination rate & $(\%)$ & \\
\hline AV-T & $7.0 \pm 3.8$ & 0 & 0 & $0.5 \pm 0.5$ & $19.0 \pm 4.3$ & $20.0 \pm 4.7$ & $20.0 \pm 4.7$ \\
\hline AV-B & $3.0 \pm 2.0$ & 0 & 0 & $0.5 \pm 0.5$ & $20.0 \pm 5.2$ & $21.0 \pm 5.6$ & $21.0 \pm 5.6$ \\
\hline UV-T & $5.0 \pm 1.6$ & $1.0 \pm 1.0$ & $1.5 \pm 1.0$ & $2.0 \pm 0.9$ & $39.5 \pm 5.5$ & $41.0 \pm 5.7$ & $41.5 \pm 6.0$ \\
\hline UV-B & $3.0 \pm 2.4$ & 0 & $0.5 \pm 0.5$ & $1.0 \pm 1.0$ & $37.5 \pm 5.3$ & $39.5 \pm 4.4$ & $40.5 \pm 5.3$ \\
\hline
\end{tabular}

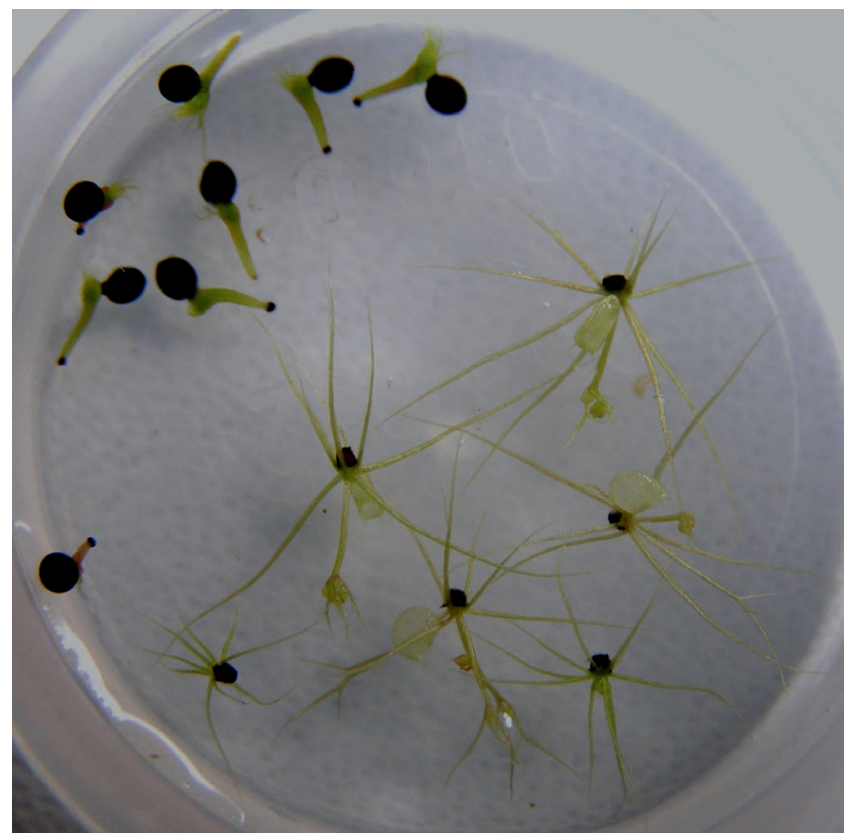

Figure 3: Germinating seeds of Aldrovanda (top) and $U$. vulgaris from the experiment. The diameter of the plastic lid is $25 \mathrm{~mm}$. Photos by Lubomír Adamec. 
The seasonal seed exposure on the top soil or 1-2 $\mathrm{cm}$ deep in the sediment had no influence on seed longevity and subsequent germination rate in Aldrovanda and U. vulgaris seeds. This indicates that a deeper anoxia is not harmful for these seeds. For both species, the germination rate in single bags was highly variable. The longevity of Aldrovanda seeds under natural conditions in water can be very variable and be shorter than one year but also longer than 2-3 years. The factors which decide seed longevity might be the population origin (temperate $v s$. subtropical), plant batch, or natural conditions on the bottom or in the sediment.

Acknowledgements: This study was funded partly by the Research Programme of the Czech Academy of Sciences (No. RVO 67985939).

\section{References}

Adamec, L. 1999a. Turion overwintering of aquatic carnivorous plants. Carniv. Pl. Newslett. 28: $19-24$.

Adamec, L. 1999b. Further notes on flowering and seed set of Aldrovanda vesiculosa. Flytrap News (Sydney) 12: 9-12.

Adamec, L. 2011. Shoot branching of the aquatic carnivorous plant Utricularia australis as the key process of plant growth. Phyton 51: 133-148.

Adamec, L., and Kučerová, A. 2013. [Rescue introductions of endangered species of aquatic plants to the Protected Landscape Area Tr̆ebon̆sko during 1994-2012.] In Czech. Issue of South Bohem. Museum in České Budějovice, Nat. Sci. 53: 59-69.

Adamec, L., and Tichý, M. 1997. Flowering of Aldrovanda vesiculosa in outdoor culture in the Czech Republic and isozyme variability of its European populations. Carniv. Pl. Newslett. 26: 99-103.

Gálová, A., and Hájková, P. 2014. [Utricularia vulgaris in Hodonínská Dúbrava.] In Czech. Zprávy České bot. spol. (Prague) 49: 261-271.

Holzbauerová, H. 2015. [Germination Tests of The Aquatic Carnivorous Plant Utricularia vulgaris.] In Czech. MSc-thesis, Fac. Sci., Univ. Hradec Králové, Czech Rep., 90 p.

Cross, A.T. 2012. Aldrovanda. The Waterwheel Plant. Redfern Natural History Production, Poole, Dorset, U.K.

Cross, A.T., Adamec, L., Turner, S.R., Dixon, K.W., and Merritt, D.J. 2016. Seed reproductive biology of the rare aquatic carnivorous plant Aldrovanda vesiculosa (Droseraceae). Bot. J. Linn. Soc. 180: 515-529.

Cross, A.T., Davis, A.R., Fleischmann, A., Horner, J.D., Jürgens, A., Merritt, D.J., Murza, G.L., and Turner, S.R. 2018. Reproductive biology and prey-pollinator conflicts. In: Ellison, A.M., and Adamec, L. (eds.), Carnivorous plants: physiology, ecology, and evolution. Oxford University Press, Oxford, U.K., pp. 294-313.

Cross, A.T., Skates, L.M., Adamec, L., Hammond, C.M., Sheridan, P.M., and Dixon, K.W. 2015. Population ecology of the endangered aquatic carnivorous macrophyte Aldrovanda vesiculosa at a naturalised site in North America. Freshwater Biol. 60: 1772-1783.

Santamaria, L. 2002. Why are most aquatic plants widely distributed? Dispersal, clonal growth and small-scale heterogeneity in a stressful environment. Acta Oecol. 23: 137-154.

Taylor, P. 1989. The genus Utricularia: a taxonomic monograph. Kew Botanic Gardens, London. 


\section{CARNIVOROUS PLANT NEWSLETTER}

Journal of the International Carnivorous Plant Society

Volume 47, No. 2

June 2018

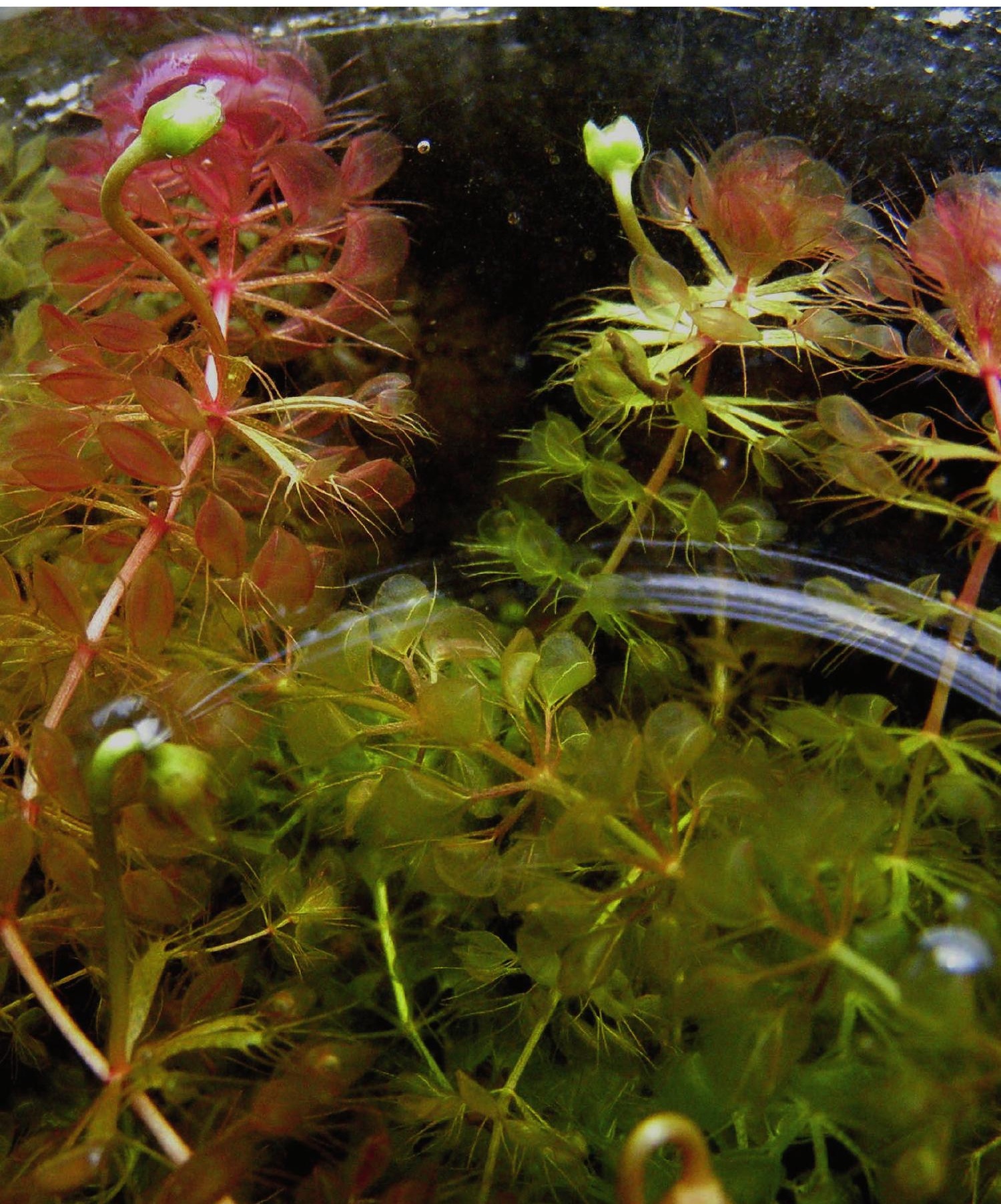




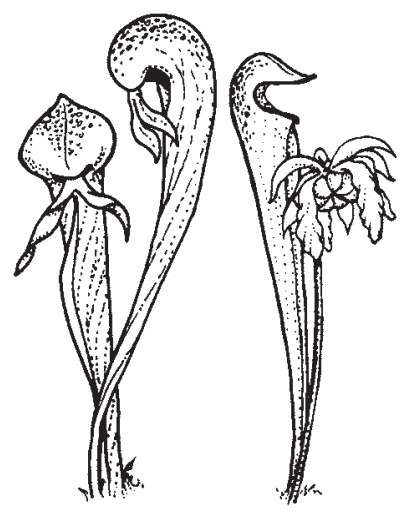

\section{CARNIVOROUS \\ PLANT \\ NEWSLETTER}

Journal of the International

Carnivorous Plant Society

www.carnivorousplants.org

Volume 47, Number 2 June 2018

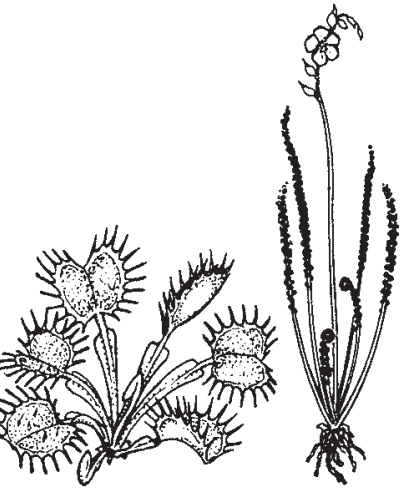

\section{Front Cover: Flowering African Aldrovanda vesiculosa from Botswana in an indoor culture. Photo by Lubomír Adamec. Article on page 64.}

\section{Back Cover: A cluster of Nepenthes ampullaria lower pitchers growing in Gunung Mulu National Park, Borneo. Photo taken by Richard Nunn. Article on page 47.}

Carnivorous Plant Newsletter is dedicated to spreading knowledge and news related to carnivorous plants. Reader contributions are essential for this mission to be successful. Do not hesitate to contact the editors with information about your plants, conservation projects, field trips, or noteworthy events. Advertisers should contact the editors. Views expressed in this publication are those of the authors, not the editorial staff.

All correspondence regarding dues, address changes and missing issues should be sent to the Membership Coordinator at the ICPS. Do not send such correspondence to the editors. Checks for subscriptions should be made to the International Carnivorous Plant Society in US funds. Dues, including a subscription, are \$30 per year.

International Carnivorous Plant Society, Inc.

2121 N. California Blvd., Suite 290

Walnut Creek, CA 94596-7351, USA

icps@carnivorousplants.org

President

Vice President

Secretary

Treasurer

Board Member

Board Member

Board Member

Membership Coordinator

Webmaster

Media Coordinator

Seed Bank Manager

CPN Editors

Managing Editor

Editor

Editor

Editor

Science Editor

Science Editor

\author{
Marcel van den Broek, marcel@carnivorousplants.org \\ Richard Nunn, richardnunn@carnivorousplants.org \\ Keith Becker, keith@carnivorousplants.org \\ Ryan Ward, ryan@carnivorousplants.org \\ Alex Eilts, Conservation Director, alex@carnivorousplants.org \\ Jan Schlauer, Cultivar Registrar, jan@carnivorousplants.org \\ Bob Ziemer, bob@carnivorousplants.org \\ Carolyn Becker, carolyn@carnivorousplants.org \\ John Brittnacher, john@carnivorousplants.org \\ ChadWilliams, chad@carnivorousplants.org \\ Joe Griffin, joe@carnivorousplants.org \\ editor@carnivorousplants.org \\ Bob Ziemer \\ Barry Rice \\ Karl Herold \\ John Brittnacher \\ Fernando Rivadavia \\ Jan Schlauer
}

Date of effective publication of the March 2018 issue of Carnivorous Plant Newsletter: 1 February 2018.

The ICPS is the International Cultivar Registration Authority (ICRA) for the names of cultivated carnivorous plants according to the International Code of Nomenclature for Cultivated Plants. Send relevant correspondence to the ICPS, Inc.

Carnivorous Plant Newsletter is published quarterly in March, June, September, and December by the ICPS, Inc., 2121 N. California Blvd., Suite 290, Walnut Creek, CA 94596, USA. Periodicals postage paid at Walnut Creek, CA and additional mailing offices. Postmaster: Send address changes to ICPS, Inc., 2121 N. California Blvd., Suite 290, Walnut Creek, CA 94596, USA. Printed by Allen Press, Inc., 810 E. 10th Street, Lawrence, KS 66044. Logo and masthead art: Paul Milauskas. (C) 2018 International Carnivorous Plant Society. All rights reserved. ISSN \#0190-9215 